\title{
Longevity and relationships with children: the importance of the
} parental role

\author{
Maria-Victoria Zunzunegui*1, François Béland², Maria-Teresa Sanchez ${ }^{3}$ and \\ Angel Otero ${ }^{3}$
}

Address: ${ }^{1}$ Département de Médecine Sociale et Préventive, Université de Montréal, Montréal, Canada, ${ }^{2}$ Département de l'Administration de la Santé, Université de Montréal; Codirector - SOLIDAGE, Lady Davis Institute, Jewish General Hospital of Montreal, Montréal, Canada and ${ }^{3}$ Departamento de Medicina Preventiva, Universidad Autónoma de Madrid, Madrid, Spain. Hospital Universitario La Paz, Madrid, Spain

Email: Maria-Victoria Zunzunegui* - maria.victoria.zunzunegui@umontreal.ca; François Béland - francois.beland@umontreal.ca; MariaTeresa Sanchez - mariateresa.sanchez@uam.es; Angel Otero - angel.otero@uam.es

* Corresponding author

Published: 18 September 2009

BMC Public Health 2009, 9:35I doi: |0.1 I86/I47|-2458-9-35 I
Received: 9 May 2009

Accepted: 18 September 2009

This article is available from: http://www.biomedcentral.com/I47I-2458/9/35 I

(C) 2009 Zunzunegui et al; licensee BioMed Central Ltd.

This is an Open Access article distributed under the terms of the Creative Commons Attribution License (http://creativecommons.org/licenses/by/2.0), which permits unrestricted use, distribution, and reproduction in any medium, provided the original work is properly cited.

\begin{abstract}
Background: Social networks predict longevity across societies but specific mechanisms are largely unknown. The aim of this work was to examine the role of children in the longevity of elderly men and women in a cohort of community dwelling elderly people in Spain.

Methods: The data were taken from the "Aging in Leganes" cohort study with 15 years of followup. The baseline population was an age- and sex-stratified random sample of community dwelling people over 65 living in Leganés (Madrid) in 1993. Poor relationship with at least one child, emotional support and the perceived roles elders play in the lives of their children, extended family, spouse and friends were assessed at baseline. Cox proportional hazards models were fit to investigate the effects of social roles variables on longevity, adjusting for a wide range of socioeconomic, behavioural and health covariates.
\end{abstract}

Results: In the fully adjusted model, having a poor relationship with at least one child increased mortality by $30 \%$. Elderly persons who felt their role in their children's lives was important $(H R=$ $0.70 ; 95 \% \mathrm{Cl} 0.54 ; 0.91$ ) had a lower mortality risk than those who felt they played a small role. Feeling loved and listened to by one's children did not have an effect on survival. Maintaining an important role in the extended family was also significantly associated with survival.

Conclusion: In this Mediterranean population, maintaining an important role in the lives of one's children is associated with survival. Functions of social networks related to meaning of life and different forms of social support may have important effects on mortality, and these functions may vary across cultures according to family norms and values.

\section{Background}

Social networks predict longevity across societies [1-7]. Pioneer studies have examined the effects of social ties on survival using overall measures of social connectedness
$[2,3,7,8]$. More recent studies from North America, Europe, Japan and Australia have found positive associations between longevity and social integration in the community [9-13], being married $[12,14]$ and having friends 
$[6,12,15]$. The impact of relationships with one's adult children on mortality has rarely been examined. Silverstein \& Bengston [16] in California reported that children's support had no general effect on survival, but that affection from children could attenuate the impact of recent widowhood on mortality. A comparative study of the role of social networks in the longevity of Swedish and American elders found that children were important for the longevity of Swedish elderly people, whereas friends and spouse were more salient for the elderly in the U.S., despite the fact that the frequency of contacts with children was similar in the two countries [5]. An Australian study reported negligible effects of social networks with children on their parents' longevity [1]. Thus, research on aspects of the relationships of elderly people with their children and survival has produced conflicting results across the few regions of the world where this research has been undertaken.

These conflicting results are also found when research is extended to include health outcomes. Thus, European studies have shown positive effects of relationships with children on elderly parent's health [17-19] but results were not replicated in two Canadian samples using similar measurement instruments [20]. A study in the United States examining the role of social support in disablement found significant associations for support from spouse and friends, but no association between support from children and risk of disability [21].

Berkman \& Glass have proposed a theoretical model according to which culture, political context and social change determine social networks which, in turn, influence health via psychological and physiological pathways [22]. We propose an additional mechanism by which social relations may influence survival status: reinforcement of social roles through recognition of the marital, parental, familial or friendship role by spouse, children, relatives and friends. We argue that in cultures where filial obligation prevails in a context of intergenerational interdependence, reinforcement of the parental role will have beneficial effects for elderly parents' survival, independently of other components of social networks (such as spouse, friends and community integration). In addition, in familial societies such as those prevailing in the Mediterranean region, the recognition of the role of the elderly by the younger members of the family may also contribute to their survival.

Many studies on social relationships and health have used the social exchange theory to explain the dynamics of these relationships [23-27]. According to this theory, social relationships are governed by a norm of reciprocity [28]. Studies on social relationships and longevity based on social exchange theories have attempted to explain how the elderly person receives social support and how this type of support affects longevity. However, few studies have examined the importance of mutual dependence for the elderly themselves. Mutual dependence builds cohesion in primary relationships such as those that tend to be found in families [28]. For elderly people, approval, affirmation and respect may be highly valued; recognition of experience and respect from their family will give meaning to life. Krause proposes that meaning to life is linked to receiving emotional support, anticipated support and negative interactions[29]. He also proposes that playing a role in a valued social institution could foster the sense of meaning to life[29]. We add that for many countries and cultures the family is a valuable social institution and that playing a role in the family and, particularly, a parental role will increase meaning to life and indirectly will increase longevity. In this paper, we present the results of a study with 15 years of follow-up data, focusing on the role of social networks with children on longevity. The aim of this work was to examine the extent to which reinforcement of the parental social roles through recognition by children is associated with longevity of elderly men and women in a cohort of community dwelling elderly population in Spain.

\section{Methods}

The data were taken from the "Aging in Leganes" cohort study (1993-2008) with 15 years of follow-up. Its main objective was to assess the impact of social relationships on the physical and mental health of a community dwelling elderly population. The study population was an ageand sex-stratified random sample $(\mathrm{n}=1560)$ of community dwelling people over age 65 (range 65-101) living in Leganés, a suburban municipality located 8 kilometres outside Madrid. The response rate was $82 \%(n=1283)$. The sample was representative of the elderly people in Leganés, whose age, sex, marital status and education resemble those of the Spanish elderly population as a whole. In 1993, only $2 \%$ of the elderly in Spain were institutionalized. Close to $93 \%$ of the participants had children and $45 \%$ of them co-resided with them. Baseline data were collected in 1993, through home interviews and a medical exam. For this paper, the sample consisted of participants who had children $(n=1186)$, were able to answer the questionnaire on social network characteristics entirely by themselves, and for whom complete data were available on all covariates $(\mathrm{n}=903)$. Those with children and incomplete data $(\mathrm{n}=283)$ had significantly higher mortality, were older, had less education and more cognitive impairment than the complete data sample $(n=903)$.

\section{Mortality}

Deaths were determined by computer linkage to the National Death Registry, upon authorization of the Ministry of Health, and using the National Identity Number, 
the first name and two last names, as is customary in Spain. All deaths occurring between study entry (April 1993-November 1993) and 31 August 2008 were ascertained. There were 863 (67.3\%) deaths among the 1283 participants older than 65 years of age in the 1993 baseline survey and 579 deaths (64.1\%) in this study sub-sample.

\section{Social networks}

Based on our literature review of the effects of social networks on health status, two dimensions of networks were measured in 1993: social support and social roles. Our main independent variable in this paper is the parental role but social support and social roles measurements were made for each of four types of networks: children, extended family (siblings, nephews and nieces, grandchildren), spouse and friends. Seven questions were asked in relation to each type of tie. The elderly participants were asked how frequently they a) felt loved and cared for; b) felt listened to; c) felt criticised; d) would like to confide more in their significant others; e) helped them; f) felt they played an important role in their lives; g) felt useful to them. Possible answers were 'never' (1 point), 'sometimes' ( 2 points), 'frequently' (3 points), and 'always' (4 points). The first two questions were taken from the MacArthur Community Study (USA) [30]. We added the last five questions to measure aspects of conflict and social roles. A factor analysis (principal axis factoring, varimax rotation) was performed. Two factors were found: Questions a) and b) scored in factor one, which was subsequently named 'received emotional support'; questions e), f) and g) scored on a second factor, which was named 'social role" To build scales, the raw item scores of the questions in each factor were added and averaged. Questions c) and d) had low loadings ( $<0.40)$ on both factors and therefore, were excluded. Cronbach's alpha varied between 0.74 and 0.83 for received emotional support and between 0.70 and 0.74 for social role. These two scales have been used in our previous work $[31,32]$.

The question on criticism (negative support) was not well accepted since elderly people said that children are not supposed to criticize their parents or relatives. Thus, to measure conflict in the relationship with children, we used participants' reports of the number of children with whom they had a good relationship. This number was subtracted from the total number of children to estimate the number of those with whom they did not have a good relationship. An indicator variable was created to distinguish those who did not have a good relationship with at least one child.

\section{Potential confounders}

Sociodemographic variables included age, sex and education. Education was categorized as: unable to read and write, no schooling but can read and write, incomplete primary, and complete primary education or more. Health status was measured by the number of chronic conditions, cognitive function and activities of daily life (ADL) disability. Chronic conditions were ascertained by asking the elderly person if he/she had been diagnosed by a doctor with any of a list of 11 chronic problems (hypertension, heart disease, circulation problems, stroke, diabetes, chronic respiratory problems, arthritis, cancer, Parkinson's disease, genitourinary and gastrointestinal problems). Cognitive function was ascertained using the Prueba Cognitiva de Leganes (PCL) [33,34], a screening test for dementia in populations with low levels of education. For descriptive purposes, the cognitive score was dichotomized at the cut-off for dementia, but used as a continuous variable in multivariate modelling. ADL disability was ascertained by asking individuals if they were able to carry out 8 activities of daily living alone, with help or not at all. Based on this information, a dichotomous variable was created with the value of 1 if the person was unable to carry out one or more activities without help and zero otherwise. Smoking was categorized as never smoked, exsmoker or currently smoking. Physical activity was coded as a dichotomous variable to distinguish those reporting light or no exercise from those reporting moderate or vigorous exercise.

Characteristics of social relationships with extended family, spouse and friends and community activities were included as potential confounders of the association between children networks and mortality, since our aim was to test if an important parental role is associated with better survival, independently of family relationships and community activities. Family roles and support were coded as explained above. An additional category was added for those without spouse or without friends. Social activities in the community were ascertained by adding the number of monthly visits to a church, a senior citizens center or the local square (equivalent to food market or neighbourhood shopping center). The cumulative number of social activities was categorized in quartiles.

\section{Statistical analysis}

Univariate Cox proportional regression models were used for each covariate to estimate hazard ratios and their 95\% confidence intervals. The assumption of proportional hazards was assessed by regressing the scaled Shoenfeld residuals against the log of time and testing for zero slope [35]

Hazard ratios (HR) for characteristics of children networks were estimated using multivariable Cox regression. We controlled for socio-demographic variables (age, sex and education), health status (number of chronic conditions, cognitive function score and ADL disability), social 
activities in the community (monthly frequency of attending religious services, social community centers for the elderly, neighbourhood square), and spouse, family and friends support and roles. The functional form of the mortality hazards of continuous variables was explored (age, number of chronic conditions, cognitive score) and linearity was accepted for all of them. For social network variables we used categories (tertiles) in order to illustrate the presence or absence of possible thresholds. Variables were included sequentially in the model: first socio-demographics; second, health and disability status indicators and third, social network variables. All interactions of social network variables with sex were tested given the conflicting results of research on gender differences in the relationships between social networks and mortality [36]. SPSS version 16 was used for factor and survival analysis.

\section{Ethical aspects}

This study has been approved by the Ethics Committee for Clinical Research of the IX Health Region of Madrid (Hospital Severo Ochoa de Leganés) and by the Ethics Committee for Research at the Universidad Autónoma de Madrid.

\section{Results}

The mean age of the analytical sample was $75.5 \pm 7.3$ years, $64 \%$ were married and level of education was low: $15 \%$ were illiterate and only $20 \%$ had finished primary education. The prevalence of ADL disability reached $24 \%$ and $78 \%$ had two or more chronic conditions.

\section{Univariate survival analysis of characteristics of children networks}

Table 1 shows the distribution of the characteristics of children networks and their univariate hazard ratios. Conflict in the relationship with children and the perceived importance of the role these elders played in their children's lives ("parental role") were associated with survival. Those who had a poor relationship with at least one child had a higher mortality risk than those who reported good relationships with each child. The association between parental role and mortality showed a dose response trend. Those who reported that they played an important parental role for their children had the lowest mortality risk, and those who considered their role somewhat important had a lower risk than those who perceived to play a small role. Children's emotional support at baseline was not associated with mortality.

\section{Univariate survival analysis of sociodemographic, health and social networks potential confounders}

Table 2 shows the distribution of the potential sociodemographic and health confounders with their univariate hazard ratios and 95\% confidence intervals. As expected, mortality risk increased with advancing age and was higher in men, widows, and those with little education. Cognitive function, ADL disability, and chronic conditions were all significantly associated with survival in this univariate analysis. Physical activity and never having smoked were also associated with survival.

The results of the univariate analysis for social network characteristics other than children networks are shown in table 3. Similar results were obtained for the role of elders in the lives of their extended family ("family role") and in their spouse's life ("marital role"), and for emotional support received from the spouse. Those without a spouse had a mortality risk similar to those who did not feel important for their spouse. Playing an important role in the lives of friends ( "friendship role") was associated with lower mortality, but mortality in those who did not consider they played an important role in this respect was similar to mortality in those who had no friends. Emotional support from friends was significantly associated with survival. Also the frequency of activities in the community was associated with survival, but in a non linear fashion.

\section{Multivariate survival analysis}

The associations between children networks and mortality are presented in Table 4 . Three models were fitted, and the results from the univariate analyses were confirmed

Table I: Children's networks characteristics: Univariate Hazard Ratios and 95\% Cls for mortality at I5 years

\begin{tabular}{|c|c|c|c|c|c|}
\hline & $\mathbf{N}$ & $\%$ deaths & HR & $95 \% \mathrm{Cl}$ & p-value \\
\hline Poor relationship with at least one child & & & & & $<0.001$ \\
\hline No & 793 & 62.3 & 1.0 & & \\
\hline Yes & 110 & 77.3 & 1.58 & $(1.26 ; 1.99)$ & \\
\hline Parental role & & & & & $<0.001$ \\
\hline Small & 259 & 78.4 & 1.0 & & \\
\hline Some & 335 & 64.2 & 0.65 & $(0.59 ; 0.79)$ & \\
\hline Important & 309 & 52.1 & 0.47 & $(0.38 ; 0.58)$ & \\
\hline Emotional support from children & & & & & 0.395 \\
\hline Low & 216 & 66.2 & 1.0 & & \\
\hline Medium & 285 & 66.0 & 0.98 & $(0.79 ; 1.22)$ & \\
\hline High & 402 & 61.8 & 0.86 & $(0.70 ; 1.06)$ & \\
\hline
\end{tabular}


Table 2: Univariate Hazard Ratios and $\mathbf{9 5 \%}$ Cls for mortality by sociodemographic and health characteristics

\begin{tabular}{|c|c|c|c|c|c|}
\hline Characteristic & $\mathbf{N}$ & $\%$ deaths & Crude HR & $95 \% \mathrm{Cl}$ & p-value \\
\hline Age & & & & & $<0.001$ \\
\hline $65-69$ & 229 & 35.8 & 1.0 & & \\
\hline $70-74$ & 215 & 54.0 & 1.74 & $(1.31 ; 2.30)$ & \\
\hline $75-79$ & 191 & 71.7 & 2.83 & $(2.15 ; 3.73)$ & \\
\hline $80-84$ & 150 & 87.3 & 4.55 & $(3.44 ; 6.01)$ & \\
\hline $85+$ & 118 & 95.8 & 7.91 & $(5.91 ; 10.58)$ & \\
\hline Sex & & & & & 0.001 \\
\hline Men & 476 & 71.2 & 1.53 & $(1.30 ; 1.81)$ & \\
\hline Women & 427 & 56.2 & 1.0 & & \\
\hline Marital status & & & & & $<0.001$ \\
\hline Widow & 316 & 71.5 & 1.46 & $(1.23 ; 1.72)$ & \\
\hline Married & 587 & 60.1 & 1.0 & & \\
\hline Education & & & & & 0.035 \\
\hline Illiterate & 137 & 72.3 & 1.46 & $(1.11 ; 1.91)$ & \\
\hline At least read and write & 270 & 63.7 & 1.16 & $(0.91 ; 1.48)$ & \\
\hline Incomplete primary & 317 & 63.7 & 1.07 & $(0.85 ; 1.36)$ & \\
\hline Primary and more & 179 & 59.2 & 1.0 & & \\
\hline Number of chronic diseases & & & & & 0.022 \\
\hline Zero or one & 153 & 56.2 & 1.0 & & \\
\hline Two or three & 365 & 64.4 & 1.25 & $(0.98 ; 1.60)$ & \\
\hline Four to five & 277 & 64.6 & 1.25 & $(0.97 ; 1.62)$ & \\
\hline Six and more & 108 & 73.1 & 1.62 & $(1.19 ; 2.20)$ & \\
\hline Cognitive function score & & & & & $<0.001$ \\
\hline$<23$ & 211 & 78.7 & 1.78 & $(1.49 ; 2.14)$ & \\
\hline$\geq 24$ & 692 & 59.7 & 1.0 & & \\
\hline ADL disability & & & & & $<0.001$ \\
\hline Yes & 220 & 79.1 & 1.85 & $(1.55 ; 2.21)$ & \\
\hline No & 683 & 59.3 & 1.0 & & \\
\hline Smoking & & & & & 0.001 \\
\hline Never & 520 & 59.2 & 1.0 & & \\
\hline Ex-smoker & 287 & 71.4 & 1.38 & $(1.15 ; 1.64)$ & \\
\hline Current Smoker & 95 & 68.4 & 1.30 & $(0.99 ; 1.70)$ & \\
\hline Physical exercise & & & & & $<0.001$ \\
\hline Vigorous & 23 & 21.7 & 0.15 & $(0.06 ; 0.36)$ & \\
\hline Moderate & 632 & 60.3 & 0.57 & $(0.48 ; 0.68)$ & \\
\hline Light & 245 & 77.6 & 1.0 & & \\
\hline
\end{tabular}

after controlling for all potential confounders. Estimates of hazard ratios were stable across models. In the fully adjusted model, having a poor relationship with at least one child was associated with a $30 \%$ increase in the hazard ratio for mortality (HR $=1.30 ; 95 \%$ CI $1.02 ; 1.67)$. Those elderly persons who felt they played an important role $(\mathrm{HR}=0.71 ; 95 \% \mathrm{CI} 0.55 ; 0.91)$ or some role $(\mathrm{HR}=$ $0.91 ; 95 \%$ CI 0.73 ; 1.12) for their children had a lower risk of mortality than those who felt they had a small role in their children's lives. Emotional support and feeling loved and listened to by one's children did not have a significant effect on survival. None of the interactions of social networks by sex attained statistical significance, indicating that the impact of children networks on longevity is similar in elderly men and women.

\section{Complete final multivariate model}

Table 5 shows the results for the final model, including all significant variables. An important parental role (Figure
1) and having good relationships with all children were associated with survival. Of the remaining social network characteristics, only role in the extended family was significant once the children network variables were included in the model. The support of spouse and friends and marital role were not significantly associated with survival. As expected, smoking and lack of physical activity were significant mortality risk factors, and the magnitude of their association with mortality was similar to the hazard ratios for having an important parental role and having good relationships with all children.

\section{Discussion}

Our results indicate that relationships with children have strong and important effects on elderly parents' survival and that these effects are related with the parental role and absence of conflict with children. Emotional support from children does not seem to have an independent effect on mortality. Playing an important role in the extended fam- 
Table 3: Univariate Hazard Ratios and $95 \%$ Cls for mortality by social network characteristics (other than children networks)

\begin{tabular}{|c|c|c|c|c|c|}
\hline Characteristic & $\mathbf{N}$ & $\%$ deaths & Crude HR & $95 \% \mathrm{Cl}$ & p-value \\
\hline Family role & & & & & $<0.001$ \\
\hline Small & 312 & 74.0 & 1.0 & & \\
\hline Some & 353 & 58.4 & 0.62 & $(0.51 ; 0.75)$ & \\
\hline Important & 238 & 59.7 & 0.65 & $(0.53 ; 0.80)$ & \\
\hline Emotional support received from family & & & & & 0.128 \\
\hline Low & 301 & 67.8 & 1.0 & & \\
\hline Medium & 401 & 60.6 & 0.83 & $(0.69 ; 1.00)$ & \\
\hline High & 201 & 65.7 & 0.96 & $(0.77 ; 1.20)$ & \\
\hline Marital role & & & & & $<0.001$ \\
\hline Small & 124 & 73.4 & 1.0 & & \\
\hline Some & 121 & 65.3 & 0.78 & $(0.57 ; 1.05)$ & \\
\hline Important & 328 & 53.0 & 0.57 & $(0.45 ; 0.74)$ & \\
\hline No spouse & 325 & 71.4 & 1.02 & $(0.80 ; 1.30)$ & \\
\hline Emotional support received from spouse & & & & & 0.003 \\
\hline Low & 102 & 57.8 & 1.0 & & \\
\hline Medium & 239 & 57.3 & 0.94 & $(0.69 ; 1.28)$ & \\
\hline High & 234 & 63.7 & 1.13 & $(0.83 ; 1.52)$ & \\
\hline No spouse & 325 & 71.4 & 1.50 & $(1.13 ; 2.00)$ & \\
\hline Friendship role & & & & & 0.003 \\
\hline Small & 166 & 67.5 & 1.0 & & \\
\hline Some & 129 & 57.4 & 0.73 & $(0.55 ; 0.98)$ & \\
\hline Important & 149 & 54.4 & 0.69 & $(0.52 ; 0.92)$ & \\
\hline No friends & 459 & 68.0 & 1.01 & $(0.82 ; 1.26)$ & \\
\hline Emotional support received from friends & & & & & 0.026 \\
\hline Low & 120 & 56.7 & 1.0 & & \\
\hline Medium & 81 & 60.5 & 1.07 & $(0.74 ; 1.55)$ & \\
\hline High & 245 & 61.2 & 1.17 & $(0.88 ; 1.56)$ & \\
\hline No friends & 457 & 68.3 & 1.40 & $(1.08 ; 1.82)$ & \\
\hline Activities in the community & & & & & $<0.001$ \\
\hline First quartile & 261 & 74.3 & 1.0 & & \\
\hline Second quartile & 236 & 60.6 & 0.67 & $(0.54 ; 0.83)$ & \\
\hline Third quartile & 200 & 53.0 & 0.54 & $(0.43 ; 0.69)$ & \\
\hline Fourth quartile & 206 & 66.0 & 0.74 & $(0.59 ; 0.92)$ & \\
\hline
\end{tabular}

ily is also associated with survival. However, neither emotional support from family, spouse or friends nor marital or friendship roles are associated with survival once the effect of parental and family roles are taken into account. Social activities in the community are not independently associated with survival once family relationships are considered.

We have previously shown that 6-year survival in this Spanish population was higher among elders with community involvement through social participation, those engaged in multiple roles with significant others, and those with a confidant [10]. Here, we extend the previous analyses to 15 years of follow up. The large number of deaths makes it possible to examine the functions of each type of network - children, relatives, spouse, and friends as well as social activities in the community, and particularly to make a quantitative assessment of the important role of children in the survival of elderly people.

As far as we know, this is the first study that has examined aspects of the parent-child relationship other than fre- quency of contact and social support on elderly people's survival. Our results illustrate two points: research on social networks and mortality needs to 1) examine the associations between mortality and specific social network components instead of relying on a summative index of total social networks and 2) consider functions of social networks other than social support. Our results support Krause's hypothesis on the beneficial effects of social relationships by fostering a sense of meaning to life [29] by testing it in a country where family and particularly children are central to elderly people's life.

Studies examining the role of children in their parents' survival have produced conflicting results, which may be due to cultural differences in intergenerational relationships and in the role of elders in family life. The effects of social networks of children and relatives were not significantly related to 10-year survival in a recent Australian study that used a measurement instrument similar to ours, which was also derived from Glass et al [37]. However, in the Australian study the protective effects of friends and confidants were large. In Denmark, a study 
Table 4: Adjusted Hazard Ratios and $95 \%$ Cls for mortality at I 5 years by characteristics of children networks

\begin{tabular}{|c|c|c|c|c|c|}
\hline & \multirow{2}{*}{$\begin{array}{l}\text { Poor relationship } \\
\text { with at least one } \\
\text { child }\end{array}$} & \multicolumn{2}{|c|}{ Parental role } & \multicolumn{2}{|c|}{ Emotional support received from childrer } \\
\hline & & Some vs Small & Important vs Small & Medium vs low & High vs low \\
\hline & $\begin{array}{c}\text { HR } \\
(95 \% \mathrm{Cl})\end{array}$ & $\begin{array}{c}\text { HR } \\
(95 \% \mathrm{Cl})\end{array}$ & $\begin{array}{c}\text { HR } \\
(95 \% \mathrm{Cl})\end{array}$ & $\begin{array}{c}\text { HR } \\
(95 \% \mathrm{Cl})\end{array}$ & $\begin{array}{c}\text { HR } \\
(95 \% \mathrm{Cl})\end{array}$ \\
\hline \multicolumn{6}{|l|}{ Model I } \\
\hline $\begin{array}{l}\text { adjusted for age, sex, } \\
\text { education }\end{array}$ & $\begin{array}{c}1.43 \\
(1.12 ; 1.82)\end{array}$ & $0.73(0.60 ; 0.89)$ & $\begin{array}{c}0.60 \\
(0.48 ; 0.75)\end{array}$ & $1.13(0.90 ; 1.43)$ & $1.05(0.84 ; 1.30)$ \\
\hline \multicolumn{6}{|l|}{ Model 2} \\
\hline $\begin{array}{l}\text { Model I+ number of } \\
\text { chronic conditions, } \\
\text { cognition and ADL } \\
\text { disability, physical activity } \\
\text { and smoking }\end{array}$ & $\begin{array}{c}1.33 \\
(1.04 ; 1.69)\end{array}$ & $0.82(0.67 ; 1.00)$ & $0.67(0.52 ; 0.83)$ & $1,09(0.86 ; 1.38)$ & $1.01(0.81 ; 1.26)$ \\
\hline \multicolumn{6}{|l|}{ Model 3} \\
\hline $\begin{array}{l}\text { Model } 2+\text { marital } \\
\text { support and usefulness, } \\
\text { family support and } \\
\text { usefulness, Friends' } \\
\text { support and usefulness, } \\
\text { frequency of community } \\
\text { activities }\end{array}$ & $\begin{array}{c}1.30 \\
(1.02 ; 1.67)\end{array}$ & $0.91(0.73 ; 1.12)$ & $\begin{array}{c}0.71 \\
(0.55 ; 0.91)\end{array}$ & $1.13(0.90 ; 1.43)$ & $\begin{array}{c}1.07 \\
(0.86 ; 1.33)\end{array}$ \\
\hline
\end{tabular}

carried out on a cohort of twins reported significant effects for relationships with co-twin, spouse and friends, but no effects of children networks on parental mortality risk were observed [6]. Children's impact on parents' longevity is likely to be more salient in societies where contacts tend to occur on a daily basis and where co-residence is frequent. As many as $40 \%$ of the elderly over 65 live with their children in the South of Europe, whereas this percentage is less than $15 \%$ in Northern Europe and even lower in North America [38]. Institutionalization is still rare in Southern Europe; in Spain around 4\% of all elderly people over 65 were institutionalized in 2007. Studies from Asia and Latin America have shown that co-residence remains the norm.

Our study has similarities with a 6-year follow-up study that examined the impact on mortality of subjective usefulness, assessed by a single question - "How do you evaluate your present usefulness to others and society?" among the elderly population in a rural area of Japan [39]. The mortality hazard in those who rated their usefulness as low was 2.24 (95\% CI 1.2; 4.3) times higher than in those who considered themselves quite useful. A study from California reported that feeling useful to friends and family was associated with lower mortality in a 7-year follow-up period [40].

Absence of conflict seems to increase survival[41]. To our knowledge, this is the first study that has attempted to measure the association between poor relationships with children and survival.

Some limitations need to be mentioned. Selection bias may be an issue since those who could not respond to the questionnaire on social networks had more cognitive impairment (mean cognitive score of 15 for excluded subjects compared with 25 for those included, the maximum score being 32). This limitation is common to studies which require self reported information on characteristics of social networks. Second, we had no information on diet or eating habits. Eating in the company of the family may increase the probability of achieving a balanced diet as opposed to the diet of elderly people living alone or living only with their spouse. Resource sharing and mutual help may increase well-being and longevity through adoption of healthy behaviours [27]. Lastly, the interactions between changes in social or health status and children networks were not tested in our relatively small sample.

The distribution of this elderly population in Leganes was similar in terms of age, sex, education, marital status and self-perceived health to the elderly Spanish population that participated in the first National Health Survey of Spain in 1993. Nevertheless, socioeconomic and cultural differences across the regions of Spain are large, although social exchanges between parents and children are extensive and similar to the situation in other Mediterranean countries [38]. Further research is needed to assess the 
Table 5: Multivariate hazards ratios: Children networks and all significant social network, health, health habits and sociodemographic variables

\begin{tabular}{|c|c|c|c|}
\hline & HR & $95 \% \mathrm{Cl}$ & p-value \\
\hline Poor relationship with at least one child & & & 0.034 \\
\hline 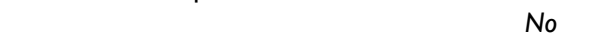 & 1.0 & & \\
\hline Yes & 1.30 & $(1.02 ; 1.66)$ & \\
\hline Parental role & & & 0.021 \\
\hline Small & 1.0 & & \\
\hline Some & 0.91 & $(0.73 ; I .13)$ & \\
\hline Important & 0.70 & $(0.54 ; 0.91)$ & \\
\hline Emotional support from children & & & 0.662 \\
\hline mos & 1.0 & & \\
\hline Medium & 1.12 & $(0.89 ; \mid .43)$ & \\
\hline High & 1.05 & $(0.84 ; 1.32)$ & \\
\hline Family role & & & 0.007 \\
\hline Small & 1.0 & & \\
\hline Some & 0.72 & $(0.58 ; 0.89)$ & \\
\hline Important & 0.89 & $(0.69 ; 1.14)$ & \\
\hline Sex & & & 0.010 \\
\hline Women & 1.0 & & \\
\hline Men & 1.40 & $(1.08 ; 1.82)$ & \\
\hline Education & & & 0.080 \\
\hline Literacy & 1.0 & & \\
\hline Illiteracy & 1.23 & $(0.98 ; \mid .55)$ & \\
\hline Age (one additional year) & 1.09 & $(1.07 ; 1.10)$ & $<0.001$ \\
\hline Cognitive function score (one additional unit) & 0.97 & $(0.95 ; 0.99)$ & 0.005 \\
\hline Comorbidity (one additional chronic disease) & 1.08 & $(1.03 ; 1.13)$ & 0.002 \\
\hline Smoking & & & 0.027 \\
\hline No smoker & 1.0 & & \\
\hline Ex-smoker & 1.36 & $(1.05 ; 1.77)$ & \\
\hline Smoker & 1.50 & $(1.08 ; 2.08)$ & \\
\hline Physical activity & & & 0.002 \\
\hline Light & 1.0 & & \\
\hline Vigorous & 0.23 & $(0.09 ; 0.56)$ & \\
\hline Moderate & 0.83 & $(0.68 ; 1.00)$ & \\
\hline
\end{tabular}

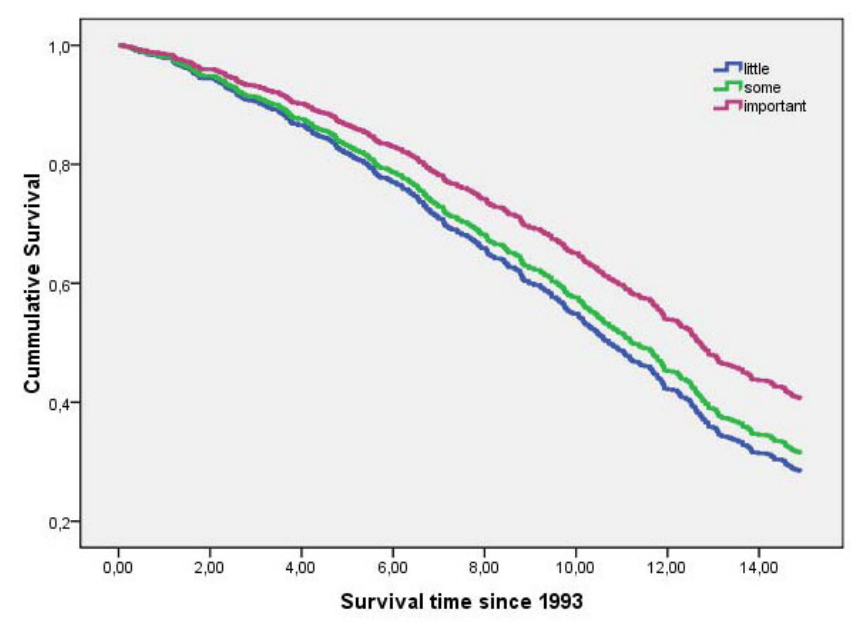

Figure I

Fifteen year survival by importance of parental role. applicability of these results to different cultures since the value of mutual and intergenerational dependence varies across cultures.

\section{Conclusion}

The results of this study contribute to the evidence of the contribution of social engagement on valuable social institutions such as the family to a sense of meaning of life that leads to increase longevity. In this Mediterranean population, family and parental roles are important predictors of survival for elderly parents. Recognition by children and the extended family of the important role of elderly family members can reinforce their feelings of usefulness, mutual dependence, and belonging, acting on survival by physiological mechanisms which are not yet understood.

\section{Competing interests}

The authors declare that they have no competing interests. 


\section{Authors' contributions}

MVZ conceived of the study, conducted the analysis of the data and wrote the first draft, FB contributed to the conception of the study and has given comments to all versions of the manuscript, MT Sanchez helped in the reference review and contributed to the data analysis and A Otero has contributed at all stages of the manuscript. All authors read and approved the final manuscript.

\section{Acknowledgements}

We thank the elderly people of Leganes for their generous contribution to our study during 15 years. We thank Ms Kathy Fitch for her excellent editorial assistance.

This work was supported by the National Fund for Health Research (Fondo de Investigaciones en Salud) of Spain (project numbers FIS PI 051898 and RETICEF RD06/00I3/1013).

\section{References}

I. Giles LC, Glonek GF, Luszcz MA, Andrews GR: Effect of social networks on 10 year survival in very old Australians: the Australian longitudinal study of aging. J Epidemiol Community Health 2005, 59(7):574-579.

2. Seeman TE, Kaplan GA, Knudsen L, Cohen R, Guralnik J: Social network ties and mortality among the elderly in the Alameda County Study. Am J Epidemiol 1987, I 26(4):7|4-723.

3. Schoenbach VJ, Kaplan BH, Fredman L, Kleinbaum DG: Social ties and mortality in Evans County, Georgia. Am J Epidemiol 1986, I 23(4):577-59|

4. Giles LC, Metcalf PA, Anderson CS, Andrews GR: Social networks among older Australians: a validation of Glass's model. J Cancer Epidemiol Prev 2002, 7(4): 195-204.

5. Eriksson BG, Hessler RM, Sundh V, Steen B: Cross-cultural analysis of longevity among Swedish and American elders: the role of social networks in the Gothenburg and Missouri longitudinal studies compared. Arch Gerontol Geriatr 1999, 28(2): $|3|-\mid 48$.

6. Rasulo D, Christensen $K$, Tomassini $C$ : The influence of social relations on mortality in later life: a study on elderly Danish twins. Gerontologist 2005, 45(5):60I-608.

7. House JS, Landis KR, Umberson D: Social relationships and health. Science 1988, 24I(4865):540-545

8. Berkman LF, Syme SL: Social networks, host resistance, and mortality: a nine-year follow-up study of Alameda County residents. Am J Epidemiol 1979, I09(2): 186-204.

9. Bowling A, Grundy E: Differentials in mortality up to 20 years after baseline interview among older people in East London and Essex. Age Ageing 2009, 38(I):5 I-55.

10. Rodriguez-Laso A, Zunzunegui MV, Otero A: The effect of social relationships on survival in elderly residents of a Southern European community: a cohort study. BMC Geriatr 2007, 7:19.

II. Glass TA, de Leon CM, Marottoli RA, Berkman LF: Population based study of social and productive activities as predictors of survival among elderly Americans. BMJ 1999, 3 I 9(7208):478-483.

12. Kaplan GA, Wilson TW, Cohen RD, Kauhanen J, Wu M, Salonen JT: Social functioning and overall mortality: prospective evidence from the Kuopio Ischemic Heart Disease Risk Factor Study. Epidemiology 1994, 5(5):495-500.

13. Avlund K, Damsgaard MT, Holstein BE: Social relations and mortality. An eleven year follow-up study of 70-year-old men and women in Denmark. Soc Sci Med I998, 47(5):635-643.

14. Ikeda A, Iso H, Toyoshima H, Fujino Y, Mizoue T, Yoshimura T, Inaba Y, Tamakoshi A, Group JS: Marital status and mortality among Japanese men and women: the Japan Collaborative Cohort Study. BMC Public Health 2007, 7:73.

15. Guilley E, Pin S, Spini D, d'Epinay CL, Herrmann F, Michel JP: Association between social relationships and survival of Swiss octogenarians. A five-year prospective, population-based study. Aging Clin Exp Res 2005, I 7(5):419-425.
16. Silverstein M, Bengtson VL: Do close parent-child relations reduce the mortality risk of older parents? J Health Soc Behav |99|, 32(4):382-395.

17. Buber IEH: Children's impact on the mental health of their older mothers and fathers: findings from the Survey of Health, Aging and Retirement in Europe. European Journal of Ageing 2008, 5(I):31-45.

18. Zunzunegui MV, Rodriguez-Laso A, Otero A, Pluijm SMF, Nikula S, Blumstein T, Jylha M, Minicucci N, Deeg DJH: Disability and social ties: Comparative findings of the CLESA study. European Journal of Ageing 2005, 2(I):40-47.

19. Zunzunegui MV, Beland F, Otero A: Support from children, living arrangements, self-rated health and depressive symptoms of older people in Spain. Int J Epidemiol 2001, 30(5): I090-I099.

20. Zunzunegui MV, Kone A, Johri M, Beland F, Wolfson C, Bergman H: Social networks and self-rated health in two French-speaking Canadian community dwelling populations over 65 . Soc Sci Med 2004, 58(I 0):2069-208I.

21. Mendes de Leon CF, Glass TA, Beckett LA, Seeman TE, Evans DA, Berkman LF: Social networks and disability transitions across eight intervals of yearly data in the New Haven EPESE. J Gerontol B Psychol Sci Soc Sci 1999, 54(3):SI62-I 72.

22. Berkman LF, Glass T, Brissette I, Seeman TE: From social integration to health: Durkheim in the new millennium. Soc Sci Med 2000, 5 I (6):843-857.

23. Bengtson VL, Burgess EO, Parrott TM: Theory, explanation, and a third generation of theoretical development in social gerontology. J Gerontol B Psychol Sci Soc Sci 1997, 52(2):S72-88.

24. Morgan DL, Schuster TL, Butler EW: Role reversals in the exchange of social support. J Gerontol I99I, 46(5):S278-287.

25. Bengtson VL, Dowd JJ: Sociological functionalism, exchange theory and life-cycle analysis: a call for more explicit theoretical bridges. Int J Aging Hum Dev 1980, I 2(I):55-73.

26. Davey A, Eggebeen DJ: Patterns of intergenerational exchange and mental health. J Gerontol B Psychol Sci Soc Sci 1998, 53(2): P86-95.

27. Umberson D: Family status and health behaviors: social control as a dimension of social integration. I Health Soc Behav 1987, 28(3):306-319.

28. Silverstein M, Conroy SJ, Wang H, Giarrusso R, Bengtson VL: Reciprocity in parent-child relations over the adult life course. J Gerontol B Psychol Sci Soc Sci 2002, 57(I):S3-I3.

29. Krause N: Deriving a Sense of Meaning in Late Life: An Overlooked Forum for the Development of Interdisciplinary Theory. In Handbook of Theories of Aging Second edition. Edited by: Bengtson VL GD, Putney NM, Silverstein M. New York: Springer Publishing Company; 2009:101-116.

30. Seeman TE, Berkman LF: Structural characteristics of social networks and their relationship with social support in the elderly: who provides support. Soc Sci Med 1988, 26(7):737-749.

31. Beland F, Zunzunegui MV, Alvarado B, Otero A, Del Ser T: Trajectories of cognitive decline and social relations. J Gerontol B Psychol Sci Soc Sci 2005, 60(6):P320-P330.

32. Zunzunegui MV, Alvarado BE, Del Ser T, Otero A: Social networks, social integration, and social engagement determine cognitive decline in community-dwelling Spanish older adults. Gerontol B Psychol Sci Soc Sci 2003, 58(2):S93-SI00.

33. Zunzunegui MV, Gutierrez Cuadra P, Beland F, Del Ser T, Wolfson C: Development of simple cognitive function measures in a community dwelling population of elderly in Spain. Int J Geriatr Psychiatry 2000, I 5(2): I30-140.

34. De Yebenes MJ, Otero A, Zunzunegui MV, Rodriguez-Laso A, Sanchez-Sanchez F, Del Ser T: Validation of a short cognitive tool for the screening of dementia in elderly people with low educational level. Int J Geriatr Psychiatry 2003, I 8( I 0):925-936.

35. Hosmer DWLS, May S: Applied Survival Analysis Hobokon: Wiley; 2007.

36. Lennartsson $C$, Silverstein $M$ : Does engagement with life enhance survival of elderly people in Sweden? The role of social and leisure activities. J Gerontol B Psychol Sci Soc Sci 200I, 56(6):S335-342.

37. Glass TA, Mendes de Leon CF, Seeman TE, Berkman LF: Beyond single indicators of social networks: a LISREL analysis of social ties among the elderly. Soc Sci Med 1997, 44( I 0): I503-I 5 I 7. 
38. Tomassini C, Glaser K, Wolf DA, Broese van Groenou MI, Grundy E: Living arrangements among older people: an overview of trends in Europe and the USA. Popul Trends 2004:24-34.

39. Okamoto $\mathrm{K}$, Tanaka $Y$ : Subjective usefulness and 6-year mortality risks among elderly persons in Japan. J Gerontol B Psychol Sci Soc Sci 2004, 59(5):P246-249.

40. Gruenewald TL, Karlamangla AS, Greendale GA, Singer BH, Seeman TE: Feelings of Usefulness to Others, Disability, and Mortality in Older Adults: the MacArthur Study of Successful Aging. J Gerontol B Psychol Sci Soc Sci 2007, 62(I):P28-37.

41. Rochette A, Gaulin P, Tellier M: Could stroke trigger be prevented by healthy family relationships? Int J Rehabil Res 2008, 32(2): $173-7$

\section{Pre-publication history}

The pre-publication history for this paper can be accessed here:

http://www.biomedcentral.com/1471-2458/9/351/pre pub

Publish with Bio Med Central and every scientist can read your work free of charge

"BioMed Central will be the most significant development for disseminating the results of biomedical research in our lifetime. "

Sir Paul Nurse, Cancer Research UK

Your research papers will be:

- available free of charge to the entire biomedical community

- peer reviewed and published immediately upon acceptance

- cited in PubMed and archived on PubMed Central

- yours - you keep the copyright 